\title{
PROJETOS ARTÍSTICOS NO DOMÍNIO DAS ARTES DE RUA NA EUROPA
}

ARTISTIC PROJECTS IN THE FIELD OF STREET ARTS IN EUROPE

\section{Bruno Costa}

Mestre em Gestão de Indústrias Criativas pela Universidade Católica Portuguesa.

E-mail: bruno.costa@bussola.com.pt.

\section{Luis Miguel Lopes Teixeira}

Professor da Escola das Artes da Universidade Católica Portuguesa. Coordenador Executivo do Mestrado em Gestão de Indústrias Criativas. Membro da direção da Escola das Artes. Doutorado em Engenharia Eletrotecnica e de Computadores.

E-mail: Iteixeira@porto.ucp.pt. 


\section{RESUMO}

A compreensão da atual realidade europeia no contexto da criação artística para o espaço público revela uma pertinência acrescida numa altura em que novos domínios da criação artística conquistam espaço na agenda europeia. Com o desenrolar deste estudo, pretendeu-se verificar e contextualizar uma nova realidade europeia no contexto da promoção e difusão de artistas e espetáculos, com impacto, ainda, ao nivel da criação. As novas orientações rumo à perspetiva transnacional levam a uma tendência de criação de redes e parcerias, mas qual o papel das redes? Com recurso à compilação bibliográfica, pretendeu-se reunir as condições necessárias para a compressão do estado da arte e da criação artística para o espaço público.

Palavras-chave: Artes de Rua. Artes Performativas. Redes Internacionais.

\section{ABSTRACT}

Understanding the current European reality in the field of artistic creation for the public space is becoming more pertinent at a time when new areas of artistic creation are gaining space in the European agenda. With the development of this study, it was intended to verify and contextualize a new European reality in the domains of promotion and diffusion of artists and performances, with impact, at the creation level. The new orientations towards the transnational perspective lead to a trend to create networks and partnerships, but what is the role of networks today? By bibliographical compilation, it was intended to gather the necessary information for the understanding of the state of art from artistic creation to public space.

Keywords: Outdoor arts. Performing arts. International networks. 


\section{INTRODUÇÃO}

O paradigma atual de financiamento aos projetos artísticos está em completa mutação. No contexto europeu, assiste-se a uma alteração da filosofia de apoio a artistas e projetos artísticos, pela revisão dos modelos de financiamento e a sua centralização no domínio do programa Europa Criativa. Este novo paradigma dá força a conceitos alternativos, como a criação de redes e parcerias entre intervenientes de diferentes países, rumo ao desenvolvimento de projetos conjuntos.

Neste sentido, importa, cada vez mais, compreender o funcionamento das redes internacionais de criação e difusão de projetos artísticos, que possibilitem a aplicação prática dos princípios que regem estes novos modelos de financiamento e o seu real impacto no mercado, possibilitando o caminho no sentido da sustentabilidade de artistas e projetos artísticos.

O mercado europeu começa a rumar no sentido das produções transnacionais e das rotas paneuropeias de apresentação e circulação de espetáculos e projetos artísticos, pelo que seja importante a compreensão das dinâmicas associadas à promoção da circulação e aos novos paradigmas da contratação de espetáculos pelas grandes estruturas e festivais. Adicionalmente, os programas de apoio aos artistas emergentes começam a surgir em destaque, pelo que também esta nova abordagem deva ser equacionada em qualquer prospeção nesta área de atividade. Assim, deverá a internacionalização, no sentido da difusão internacional dos projetos artísticos desenvolvidos, ser o caminho a seguir para os agentes artísticos? Havendo hoje motivações cada vez mais vincadas na perspetiva internacional, que envolvem a maximização do investimento, o alargamento do público potencial e mesmo as questões politico-estratégicas de nivel central que tendem para o desenvolvimento de uma identidade única europeia.

Hoje, inúmeros projetos de apoio à divulgação e difusão baseiam-se, cada vez mais, em plataformas centralizadas de informação dirigidas a produtores e programadores, com capacidade de decisão quanto à seleção e compra de projetos artísticos para apresentação ao público. A realização de eventos picth e de pré-apresentação de projetos integram também esta verdadeira rota de "industrialização" da circulação de projetos de artes de rua no continente europeu, enquanto num nicho mais reservado se continua a percecionar a velha estratégia da liberdade total da criação artística para o espaço público como antagónica da nova realidade de mercado global.

Neste contexto, será essencial compreender de que forma artistas e agentes de difusão e programação encaram estes novos desafios e se são patentes diferenças entre diferentes países e regiões no continente europeu. 


\subsection{AS ARTES DE RUA}

Contextualizando as artes de rua, como uma panóplia de manifestações artísticas no espaço público, de índole multidisciplinar, capazes de unir diversos intervenientes de múltiplas áreas artísticas, encontramos um mercado complexo e de difícil sumarização, que reúne, no mesmo espaço, o pequeno artista e gigantescas performances com megaestruturas cénicas e mesmo pirotecnia ou outros efeitos visuais. A linguagem não verbal e a abordagem alternativa às cidades e às comunidades, com projetos arrojados e interventivos, têm sido as faces mais vincadas da criação artística para o espaço público. Esta perspetiva site-specific e os projetos de larga escala têm convergido com uma linha desadequada à atual realidade de difusão, que tende a ser corrigida com novas abordagens à criação, comunicação e difusão dos projetos (FLOCH, 2007).

A definição de artes de rua tem sofrido várias mutações nas últimas décadas, sendo, em grande medida, dependente da opinião de autores e dos diversos contextos regionais. Na prática, neste domínio podem enquadrar-se diversas atividades artísticas dirigidas ao espaço público, como dança, música, pirotecnia, teatro ou performance que envolve pequenos projetos artísticos ou mesmo produções de grande formato. A tradição das artes de rua conecta-se a uma arte política, capaz de incutir nos projetos mensagens vincadas e fortes reivindicações, num trabalho que muitas vezes é largamente participativo. Como a designação indica, em modo de síntese, as artes de rua são atividades artísticas que acontecem no espaço público ou em locais de espetáculos não convencionais, com técnicas e desafios que pretendem surpreender a audiência a cada momento (Hall, 2002).

O historial das artes de rua, apesar de longo na antiguidade temporal, tem por base projetos de intervenção e de extrema liberdade criativa e irreverência, sendo que apenas surge como manifestação profissional entre as décadas de 70 e 80 do século XX, quando, em França, os artistas se uniram pela criação de condições dignas de trabalho, equilibrando os seus direitos com outras manifestações artísticas com maior reconhecimento. A partir de então, as artes de rua conquistaram uma nova dimensão, reforçada na década de 90 do século passado, mas que revelou uma difícil adaptação às mutações económicas, políticas e sociais do século XXI (RUBIO, 2011).

No contexto atual, o foco na economia criativa será certamente um caminho a trilhar também pelos artistas que trabalham as dimensões do espaço público, de forma a criar a nível local e conseguir distribuir a nivel global bens e serviços com valor simbólico e económico (FONSECA REIS, 2008). Partindo deste pressuposto, as artes de rua poderão caminhar num rumo de sustentabilidade bastante mais sólido do que o paradigma das últimas décadas. 


\section{ESTADO DAS ARTES DE RUA NA EUROPA}

Na última década, a Europa mergulhou numa crise económica complexa que a fez repensar a sua forma de estar e as conexões entre os diversos estados membros. De uma forma geral, a evolução verificada entre 2007 e 2013 revela uma diminuição quase generalizada no acesso e participação culturais, sendo que as artes de rua e outras atividades performativas não são exceção (VITORINO, 2014). Num contexto de crise social, com algumas questões étnicas e xenófobas patentes, a política central de Bruxelas tem seguido medidas de promoção da mobilidade entre os estados membros para as mais diversas áreas da economia, capazes de aumentar a diversidade e os desafios para a comunidade, reduzindo as tensões sociais e rumando para a identificação de uma identidade única europeia (EUROPEAN COMISSION, 2014a).

Este será um processo longo e que deverá cruzar várias classes sociais e sectores da economia, pelo que se perspetiva uma tendência de manutenção da aposta nos programas de coesão social, que potenciem o diálogo intercultural e a criação de bens comuns, transversais ao público de diversos países, servindo de suporte a uma democracia à escala europeia. Assim, podemos verificar um conjunto de pressupostos políticos que, não sendo diretamente dirigidos às artes e à cultura, poderão beneficiar a mobilidade de artistas e a criação de condições para coproduções, que deverão ser tidos em conta em qualquer processo de internacionalização de projetos artísticos no contexto atual.

Figura 1 - Agentes do mercado europeu das artes de rua e suas interligações

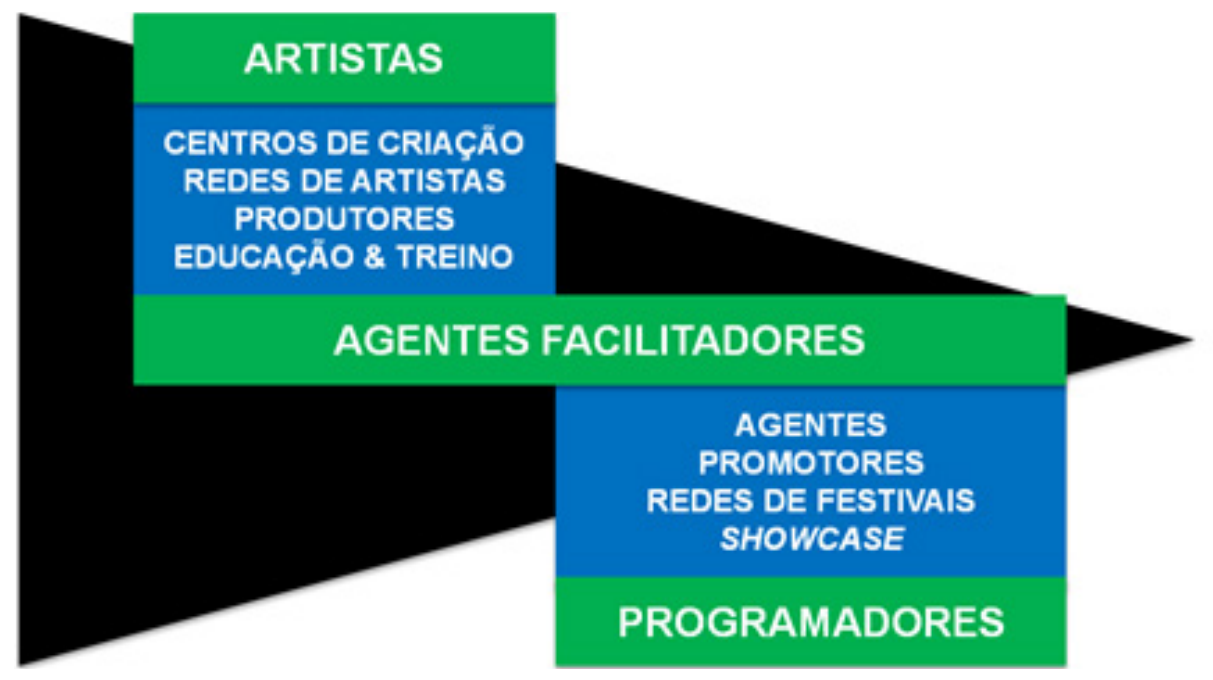


Atualmente, a tradicional abordagem artística, focada em diversos conceitos meramente conceptuais e dramatúrgicos, tende a ser substituída por uma abordagem a um mercado mais complexo e dinâmico, onde os conceitos das indústrias criativas ganham terreno, levando os diversos players a adaptarem a sua abordagem ao mercado, no sentido de uma comercialização mais vincada dos projetos artísticos, em detrimento de abordagens mais específicas. Mas será esta a única forma de encarar o atual mercado europeu das artes de rua?

A compreensão da situação atual do mercado europeu de artes de rua, no que à mobilidade e sistemas legais e de financiamento diz respeito, será um fator imperativo para uma análise ponderada das tendências no sentido da internacionalização de projetos artísticos na Europa.

\section{MOBILIDADE DE ARTISTAS DE RUA NA EUROPA}

As artes de rua são um contexto artístico com longa tradição na Europa, com uma grande expressão a partir das décadas de 60 e 70 do século passado, aquando de uma grande contestação do movimento artístico, que conduziu a transformações profundas na forma de encarar a expressão artística no espaço público (RUBIO, 2011). No entanto, a generalização deste contexto artístico no mercado europeu aconteceu apenas nas décadas de 80 e 90, numa quase reação à industrialização do mercado da cultura. Neste período, a Europa, e também Portugal, assistiu ao surgimento de um grande número de companhias organizadas e ao nascimento das criações de grande formato para o espaço público (FLOCH, 2007).

Aconquista de políticas ea criação do mercado único europeu foram fatores que, hámuito, potenciaram o incremento na mobilidade de artistas à escal a continental, potenciando a transdisciplinaridade, o trabalho conjunto ou a circulação de espetáculos. Nas últimas décadas, os fatores facilitadores da contratação ao nível legal e as facilidades ao nível das fronteiras foram motivos essenciais para uma maior mobilidade de artistas.

À entrada no século XXI encontramos um movimento artístico com forte circulação e com uma identidade única, concentrado na Europa central, essencialmente na França e em Itália. Apesar disso, os efeitos da crise económica foram patentes com claros efeitos negativos na generalidade das companhias em circulação internacional, restringindo as produções de larga escala aos principais festivais e limitando, por razões financeiras, as circulações internacionais a um número mais restrito de profissionais (RUBIO, 2011). O efeito da crise foi tão notório que o perfil que encontramos é atualmente bastante diferente, com novos países a crescer ao nível da criação artística para o espaço público, estando a Espanha, a Bélgica, a Holanda e o Reino Unido com um peso crescente na atual estrutura de mercado. 
O relatório de estado da arte da performance no espaço público na Europa, elaborado pelo Hors Les Murs para o Parlamento Europeu em 2007, dá conta da existência de mais de 600 festivais de rua na Europa, sendo 250 deles em França. Deve atender-se a que este relatório reporta a situação antes da crise financeira, mas poderá ceder-nos dados dos níveis de circulação e da mobilidade de artistas (FLOCH, 2007). Assim, em 2007, o orçamento dos festivais de rua europeus variava entre os 50 mil euros e milhão e meio de euros, sendo mais de $70 \%$ deles realizados no período entre maio e setembro. As companhias britânicas, belgas, alemãs, holandesas e espanholas eram as que atingiam maiores níveis de circulação internacional. Já nesta altura, a relação contratual dos festivais com os artistas se revestia de diversos modelos, que vão desde a cobertura total das despesas e cachets artísticos ou a sistemas mais restritivos de cobertura parcial ou apenas ajudas de custo (FLOCH, 2007).

O estudo do Hors Les Murs indica o forte potencial económico das artes de rua e a sua capacidade de mobilidade, com a criação de ligações fortes ao espaço público das cidades e a consequente criação da dimensão do turismo cultural associado aos principais festivais de rua, representando impactos diretos e indiretos na economia. Este sector contribui, ainda, para a criatividade e inovação da economia, potenciando a criação de uma identidade única europeia. No entanto, os autores sugerem a criação de sistemas que qualifiquem o mercado, contribuindo para a profissionalização através da criação de uma estrutura sólida de apoio à escala europeia. Um "novo" relatório publicado por um grupo de trabalho da Circostrada Network, em parceria com o Hors Les Murs (atualmente ARTCENA), com base nas conclusões do FRESH STREET\#1, o primeiro seminário europeu de boas práticas para as artes de rua, que aconteceu em Setembro de 20151, em Barcelona, toma a forma de manifesto com potencial de debate futuro e contributo para a evolução contínua.

A Comissão Europeia identifica, ainda, um conjunto de fatores de sucesso para a internacionalização de projetos artísticos, que incluem ações a montante e a jusante da criação artística, tais como: o contexto do projeto; a integração da cadeia de valor; acessibilidade, participação e cocriação; a mediação cultural; os instrumentos colaborativos; interculturalidade; diversidade e pluralidade de equipas de trabalho; inovação e utilização de tecnologias; a avaliação constante e as ações de disseminação (EUROPEAN COMISSION, 2014b).

\footnotetext{
${ }^{1}$ Disponível em: <http://www.circostrada.org/en/fresh-street1-european-seminar-development-street-arts>.
} 


\section{SISTEMAS DE APOIO FINANCEIRO A PROJETOS ARTÍSTICOS}

A nivel internacional encontramos formas muito distintas de financiar a cultura e a mobilidade de artistas, dentro e fora do espaço europeu. Países como o Reino Unido e os Estados Unidos apresentam modelos de financiamento bastante complexos que combinam fontes públicas (orçamento de governos centrais e regionais e benefícios fiscais) e privadas (subsídios, doações e instrumentos financeiros decorrentes de estímulos fiscais associados). No Brasil encontramos, também, um sistema particular designado Procultura², que visa aumentar e racionalizar os recursos financeiros a nivel federal, que possibilita diversos eixos de ação, desde o financiamento direto em diferentes níveis da criação e difusão até aos benefícios fiscais associados ao apoio privado (VITORINO, 2014).

Assim, no âmbito deste estudo, importa compreender o contexto europeu e observar as diferentes opções de financiamento disponíveis, atendendo, ainda, a particularidades de alguns países e a possíveis diferenças regionais, de forma a obter uma panorâmica geral da realidade europeia ao nível do financiamento para a internacionalização de projetos artísticos. Neste âmbito, serão referenciados alguns exemplos concretos, que focam a especialização nas artes de rua.

A primeira década do século XXI ficou marcada pelo programa Cultura 2000, que redefiniu as políticas de financiamento a nível europeu, com implicações nas políticas internas dos diversos estados membro. O saldo deste programa revelou-se fraco para as estruturas portuguesas, que revelaram experiência muito limitada comparativamente com outros países europeus, o que levou a limitações nos processos de candidatura com resultados claramente abaixo das expectativas (Garrett, 2002).

Importa, então, compreender a atual realidade europeia ao nível do financiamento aos artistas. Neste contexto, podemos considerar duas áreas distintas de financiamento - público e privado - com as suas consequentes particularidades e especificidades, que serão exploradas nas próximas secções do estudo.

\subsection{PROGRAMAS DE FINANCIAMENTO PÚBLICO}

Atualmente, ao nível da União Europeia, o programa Europa Criativa centraliza as perspetivas de financiamento dirigidas aos agentes artísticos e culturais, nomeadamente através da fusão dos programas

\footnotetext{
2 O Procultura - Programa de Fomento e Incentivo à Cultura é o principal sistema de financiamento à cultura no Brasil, nascendo de uma vontade de correção de assimetrias e distorções no mecanismo de incentivo fiscal. Pela primeira vez, a distribuição de verbas atende a quotas regionais, com um mínimo de 10\% para cada uma das regiões do Brasil, dando, ainda, especial atenção a empresas e entidades de dimensão mais reduzida.
} 
Cultura e Media. A sua estruturação em ciclos plurianuais mantém-se, estando atualmente vigente o período 2014-2020.

Entre 2007 e 2013, no anterior período estrutural do programa Cultura, a União Europeia disponibilizou 400 milhões de euros com vista ao estímulo da cooperação internacional, valorização do património cultural comum e da cidadania europeia, com uma atuação privilegiada nos domínios da mobilidade, circulação transnacional e diálogos interculturais (VITORINO, 2014).

No período vigente - 2014-2020 - o programa Europa Criativa tem uma dotação orçamental global de 1,46 mil milhões de euros, que inclui 750 milhões de euros para empréstimos bancários a pequenas empresas dos domínios cultural e criativo. Neste novo programa, enquadram-se projetos de cooperação interdisciplinar entre entidades de diferentes países que envolvam a transferência de competências criativas, redes de apoios aos setores culturais, tradução de obras literárias, plataformas para artistas emergentes, desenvolvimento de competências e formação, entre outras atividades no domínio do anterior programa Media (Memphis, 2014). Apesar da reformulação, o subprograma Media da Europa Criativa tem um peso muito mais significativo ao nível das verbas disponiveis relativamente ao subprograma Cultura. As candidaturas a este programa respeitam um sistema de financiamento competitivo, através de cronograma de calls dirigidas a áreas específicas.

A nova realidade de financiamento à escala europeia engloba, ainda, o programa Erasmus +, que tendo por base o suporte financeiro à educação e formação dos jovens poderá ter algum impacto no apoio a projetos de cooperação criativa que envolvam a formação e a capacitação no processo de criação, promovendo a mobilidade de artistas entre os diversos estados membro (MEMPHIS, 2014).

No contexto europeu, existe uma grande variabilidade na abordagem ao financiamento e na sensibilidade política para este nicho de trabalho artístico, resultando em contextos muito diferenciados. Neste estudo, atendendo a alguns fatores limitadores, como acesso à informação e às línguas dos documentos originais, optou-se por centrar a análise em alguns dos países com maior tradição de circulação internacional.

O Governo holandês é um exemplo diferenciador, atuando de forma direta no apoio aos artistas com datas internacionais. Qualquer performance de rua que seja aprovada através da check-list anual e tenha contratado mais de 3 apresentações para um determinado festival extrafronteiras poderá solicitar apoio direto para a cobertura integral das despesas de deslocação. Por sua vez, Espanha e Reino Unido delegam a responsabilidade da distribuição dos fundos aos conselhos de cultura dos governos regionais, fazendo aproximar a sua distribuição da realidade artística de cada região específica.

No caso português, a diferenciação regional não é notória pela especificidade da nossa divisão geográfica, mas importará compreender casos concretos no espaço europeu onde governos regionais 
centram a sua estratégia na internacionalização, com ferramentas de apoio muito concretas neste sentido (GRODACH; CURRID-HALKETT; FOSTER; MURDOCH, 2014). A região das Flanders (Bélgica) e a Catalunha (Espanha) são dois exemplos muito concretos desta especificidade regional, em grande medida motivada por antigas questões políticas e estratégicas.

O Governo Regional da Catalunha criou o Institut Català de les Empreses Culturals que funciona como uma estrutura de apoio a toda a atividade cultural e criativa da região, prestando suporte nas mais variadas áreas. Recentemente este instituto desenvolveu a plataforma Creative Catalonia, que funciona a nivel internacional como uma ferramenta de divulgação e promoção de artistas e criativos catalães, suportados numa rede ímpar de espaços de criação específicos para variadas áreas artísticas.

No sentido do apoio à mobilidade, o Governo Regional da Catalunha promove duas vezes por ano bolsas de apoio à circulação dirigidas a artistas com contratos já assinados para apresentações fora de Espanha. Estas bolsas cobrem na íntegra os gastos com as deslocações, minimizando o investimento dos promotores e facilitando a difusão internacional.

O Flanders Arts Institute ${ }^{3}$ é uma organização fundada em 2015 a partir de uma parceria entre o VTi (Institute for the Performing Arts in Flanders), o BAM (Flemish Institute for Visual, Audiovisual and Media Art) e o Flanders Music Centre, que se destina à promoção dos sectores cultural e criativo da região de uma forma sustentada. Tal como na Catalunha, o apoio à mobilidade é uma das prioridades desta organização, que também promove apoios diretos às despesas de deslocação, assim como outras atividades de promoção dos artistas da região em eventos internacionais de relevo.

A nivel nacional, em Portugal, a Secretaria de Estado da Cultura desempenha, atualmente, um papel fundamental no financiamento às artes e à cultura. Além do peso estratégico na definição de políticas e metas, chama a si uma fatia substancial dos fundos disponiveis para o apoio aos agentes artísticos e culturais, que nos últimos anos atinge valores na ordem dos 180 milhões de euros, ou seja, cerca de 0,08\% do total da despesa do Orçamento de Estado (VITORINO, 2014).

Sob alçada da Secretaria de Estado da Cultura estão entidades como a Direção Geral das Artes e o Instituto do Cinema e do Audiovisual, responsáveis pelos programas específicos de definição das metas e atribuição de financiamento. Entre outros programas de apoio, a Direção Geral das Artes dedica a cada ano um programa específico de apoio à internacionalização de projetos artísticos, promovendo a mobilidade internacional e a difusão de projetos criados em Portugal em outros países.

\footnotetext{
${ }^{3}$ Disponível em: <http://www.flandersartsinstitute.be/>.
} 
Com este processo, a Direção Geral das Artes pretende apoiar o desenvolvimento de projetos artísticos profissionais de entidades de criação, no exterior do território nacional. O programa anual de financiamento à internacionalização tem por base o contributo para a projeção internacional da cultura e das artes contemporâneas portuguesas, em particular para a difusão e o reconhecimento mais amplo do trabalho artístico português noutros países, com especial enfoque noutros Continentes.

No ano 2014 foram disponibilizados 425 mil euros para o apoio de cerca de 60 projetos artísticos, com enfoque exclusivo nas despesas diretamente relacionadas com a internacionalização. As despesas elegiveis envolvem deslocações, alojamento e despesas de preparação para outros mercados, como traduções e preparação de materiais de comunicação (DIREÇÃO GERAL DAS ARTES, 2014).

O financiamento público a nível nacional pode, também, ser efetuado a partir de apoios de fundos estruturais da União Europeia. No período entre 2007 e 2013, o QREN teve um impacto significativo no apoio a agentes culturais, com uma média anual de mais de 150 milhões de euros de fundos aplicados (VITORINO, 2014). No novo programa Portugal 2020, o apoio a agentes culturais não terá a mesma dimensão, mas, atendendo a alguns perfis específicos e atividades centradas na coesão social e na promoção da economia, como a mobilidade internacional, esta manter-se-á como uma ferramenta essencial.

\subsection{SISTEMAS DE FINANCIAMENTO PRIVADO}

No contexto atual, o financiamento privado tem um impacto cada vez maior para os artistas, devendo ser encarado como uma ferramenta possível para o desenvolvimento de projetos e o apoio à internacionalização. Crowdfunding, mecenato e programas de apoio de instituições privadas são algumas das possibilidades a considerar.

\section{Crowdfunding}

O crowdfunding representa um conceito emergente para o financiamento da inovação e de produtos com potencial de atração do grande público, mas que representam algum risco para os meios clássicos de financiamento. Corresponde ao financiamento direto pelo destinatário dos produtos, com algumas potenciais contrapartidas ou aquisição antecipada do produto, mesmo antes da sua criação ou produção. Ao nível artístico, esta ferramenta tem sido utilizada essencialmente na edição de música e de livros, com venda antecipada diretamente ao consumidor final. Existem no mercado diversas plataformas que possibilitam a gestão deste modelo de financiamento, com sede nacional e internacional, e que já apoiaram centenas de projetos à escala global. A nível internacional, as maiores plataformas gestoras de projetos 
de crowdfunding são a Go Fund Me, a Kick Starter e a Indie Go Go. Portugal tem já algumas plataformas específicas para o mercado interno, com destaque para a PPI e a Massive Crowdfunding.

\section{Mecenato}

O mecenato corresponde à atribuição de apoio financeiro direto a artistas e/ou instituiç̧ões por agentes privados. Na prática, este conceito generoso e obviamente associado à notoriedade dos mecenas, é caraterístico das práticas adotadas no Renascimento e exigiu que na atualidade Ihe fossem atribuídas vantagens materiais, como os benefícios fiscais (VITORINO, 2014). Os benefícios fiscais relativos ao mecenato referem-se, de acordo com a legislação portuguesa, a donativos em dinheiro ou em espécie, concedidos, sem contrapartidas, a entidades públicas ou privadas cuja atividade consista predominantemente na realização de iniciativas nas áreas social, cultural, ambiental, desportiva ou educacional (VITORINO, 2014). Com a redução do impacto desses benefícios, o mecenato deixou de ser representativo no apoio aos artistas.

\section{Fundações \& Outras Entidades}

Historicamente, o financiamento privado à cultura envolve um conjunto limitado de entidades, sendo estas essencialmente fundações e institutos, que focam a sua atividade ou parte dela na procura de soluções para o financiamento de artistas e projetos artísticos. A nível Europeu, o panorama é bastante complexo e diferenciado em função do historial de cada país, sendo que ao nível das artes de rua poderemos destacar a atividade do Lottery Found, no Reino Unido, como suporte financeiro a diversos artistas e plataformas que têm o espaço público como ponto essencial de atuação.

Em Portugal, embora as artes de rua não sejam o centro da atividade de nenhum dos intervenientes nesta modalidade de apoio, encontramos à cabeça a Fundação Calouste Gulbenkian, também as Fundações EDP, PT, BCP, Eugénio de Almeida, Cupertino de Miranda e Mário Soares ou a Tabaqueira S.A. como estruturas aptas a suportar as atividades de criação artística (VITORINO, 2014). Todas estas entidades desenvolvem programas de diversas índoles, abrangentes e específicas, para suporte à criação artística em diversos domínios. Nenhum deles foca especificamente as artes de rua, sendo que, na linha da performance, alguns projetos nacionais podem ser financiados por esta via.

\section{CONSIDERAÇÕES FINAIS}

No contexto atual, o financiamento para projetos artísticos reveste-se de modelos cada vez mais complexos que se centram na atividade criativa e cada vez menos nas atividades estruturais das 
companhias. A nova ideologia que suporta o programa Europa Criativa conduz o financiamento para os projetos em rede e em cooperação, dando força mais vincada à coesão social e à integração da comunidade do que ao mero trabalho artístico. Assim, o financiamento de suporte geral aos artistas deve hoje seguir linhas alternativas e centrar-se em parcerias de nivel local, nacional ou internacional.

Por outro lado, os sistemas de apoio à internacionalização e à mobilidade estão crescendo com um número cada vez maior de países e entidades a apoiarem esta linha estratégica. Neste prisma, os artistas poderão encontrar sistemas sólidos de apoio a sua circulação e apresentação de espetáculos para públicos mais vastos. No entanto, num mercado cada vez mais global, o financiamento deixa de ser o maior fator limitante para a difusão, sendo essencial encontrar plataformas de suporte à comunicação, que consigam atuar de forma direcionada e integrada, com vista a esse objetivo.

Ao nivel dos mecanismos de financiamento não centrais (Comissão Europeia) podem ser referenciadas muitas assimetrias no mercado europeu, sendo que algumas delas são de índole regional, com exemplos concretos nas regiões das Flanders (Bélgica) e da Catalunha (Espanha) que, estando dotadas de estruturas especializadas para este efeito, oferecem aos artistas dessas regiões condições beneficiadas para a mobilidade, quando comparados com outros artistas do mesmo país.

\section{REFERÊNCIAS}

Direção-Geral das Artes. Apoio à internacionalização das artes. 2014. Disponivel em: https://www. dgartes.gov.pt/pt/hist-apoio/614.

European Commission. Report on the role of public arts and cultural institutions in the promotion of cultural diversity and intercultural dialogue. Brussels: 2014a.

European Commission. Good Practice Report on the Cultural and Creative Sector's Export and Internationalisation Support Strategies, European Agenda for Culture. Brussels: 2014b.

Fonseca Reis A. Economia criativa como estratégia de desenvolvimento: uma visão dos países em desenvolvimento. São Paulo: Itaú Cultural, 2008.

Floch Y. Street Artists in Europe. Hors Les Murs: Paris, 2007.

Garrett R. Impacto e receptividade do programa Cultura 2000 em Portugal. Observatório das Atividades Culturais: 2002. 
Grodach et al. The Location Patterns of Artistic Cultures: A Metro and Neighborhood-Level Analysis. Urban Studies, 1-22, 2014.

Hall, F. Strategy and Report on Street Arts. Arts Council England: 2002.

Memphins D. Policy Handbook: Promotion of Creative Parternships. Brussels: 2014.

Rubio, J. Organising an artistic event in the public space - practical guide. Hors les Murs: Paris, 2011.

Vitorino N. Criação de Instrumentos Financeiros para Financiamento do Investimento na Cultura, Património e Indústrias Culturais e Criativas. GEPAC - Gabinete de Estratégia, Planeamento e Avaliação Culturais: 2014 